\title{
The Effect of an Off-Peak Ground Pre-Cool Control Strategy on Hybrid Ground-Source Heat Pump Systems
}

\author{
Adam A. Alaica
}

Dr. Seth B. Dworkin

\begin{abstract}
Hybrid Ground-Source Heat Pump (HGSHP) systems have been introduced as an alternate system configuration to remedy the current financial burdles associated to the installation of geo-exchange technology. However, there still remains potential for increased economic feasibility with the addition of improved system control. This study introduces an operational strategy referred to as an 'Off-Peak. Ground Pre-Cool', employing time-of-use conscious operating logic to facilitate artificial bore-field pre-conditioning. Artificially pre-cooling a system's bore-field during an off-peak operating bracket allows for improved thermal characteristics for the following peak period. With improved bore-field thermal characteristics during peak periods, cooling mode operation can be exploited more efficiently, resulting in a reduction in peak power consumption and operating costs. This study presents a preliminary evaluation of the impact the proposed off-peak ground pre-cool strategy has on the operation of a HGSHP system, simulated for a mid-rise multi-residential facility located in Toronto, Canada. Two analyses are presented simulating the strategy's impact as a function of pre-cool duration and bybrid system proportions. This study explores the potential benefit that a proactive bore-field pre-condition poses for the operation of a HGSHP system, intending to concurrently address improving system economics and aid in the balancing of the electrical grid.
\end{abstract}

\section{INTRODUCTION}

There is a prominent need for the development and integration of sustainable energy alternatives to alleviate our current dependence on energy sources that produce substantial carbon footprints. When assessing a nation's annual energy consumption, the building sector accounts for a significant portion. According to the U.S Energy Information Administration, the building sector consumed 47.6\% of total energy used in the United States, as of 2012 (EIA 2012). With space heating/cooling requirements typically accounting for $50 \%$ of a building's annual energy usage, the integration of high efficiency alternatives present the potential for a significant reduction in energy consumption, operating costs, and green-house gas emissions (NRCan 2013).

Hybrid Ground-Source Heat Pump (HGSHP) systems provide a sustainable means of space heating/cooling, pairing a geo-exchange system with auxiliary heating/cooling units, or in the case of a retrofitted installation, the existing conventional heating/cooling systems are utilized. Hybridization is used as a technique to provide flexibility in the design process, allowing for economic optimization techniques to be utilized as suggested by Alavy et al., (2013). Hybrid design procedures size the geo-exchange component to meet a percentage of buildings base load requirements. During peak hours of operation, the auxiliary system provides supplementary assistance to ensure the building's demand is met (Hackel and Pertzborn 2011). Solar assisted ground-source heat pump (SAGSHP) systems have been proposed as alternative hybrid configuration, allowing for improved heating mode efficiency by the means of a bore-field thermal 
storage strategy. This technique employs a solar thermal collector to heat the ground-loop working fluid, which is circulated through a bore-field to pre-heat the surrounding soil prior to a dwelling requiring heat. The literature suggests significant improvements in solar assistant geo-exchange system efficiency, resulting in a $28.1 \%$ increase in bore-field heat excahnge rates and $8.74 \%$ to $9.3 \%$ increase in the coefficient of performance (COP) (Nam et al. 2015; Verma and Murugesan 2014).

A performance assessment study (Jassen et al. 2015), conducted by the Toronto and Region Conservation Authority of urban geo-exchange projects in the Greater Toronto Area, presented valuable insight on various research areas to further the potential of geo-exchange technology. In this study, time-of-use (TOU) based control strategies were highlighted as an area for further research and development, indicating a potential to reduce electricity costs from 20 to $25 \%$. Aside from the cost savings associated with TOU control, additional benefits are provided to utilities in the form of electrical load leveling, which helps alleviate the pressure placed on the grid during peak hours (Jassen et al. 2015). The study presented by Carvalho et al., (2015) proposed a TOU-conscious demand side management strategy; using a GSHP as a flexible load to artificially consume energy in off-peak periods to pre-heat a service building. The building pre-heat allowed for a portion of the GSHP's operating cycles to be isolated within off-peak operating periods; resulting in a $34 \%$ reduction in electricity costs, due to reduced electricity rates.

The scope of this paper is to provide a preliminary evaluation of a proactive control strategy for cooling mode operation of HGSHP systems. Referred to as the 'off-peak ground pre-cool' (OGPC) control strategy, this methodology utilizes the auxiliary cooling system as a flexible load to artificially consume electricity during off-peak TOU brackets to remove heat from the ground, when energy costs are most economical. This study aims to demonstrate that a HGSHP system operated with an OGPC strategy can exploit the bore-field's/ground's thermal mass with a pre-cool, creating improved thermal characteristics during the following mid-peak/peak periods. With a TOU-conscious operating strategy, the proposed scheme has the potential to address improving system economics through an increase in operating efficiency and concurrently aiding in the balancing of the electrical grid.

The analysis in the present study was conducted by the use of a newly developed numerical model, characterizing the operation of a HGSHP system. The model was used to simulate the response of a HGSHP system when exposed to two operating scenarios as: (1) base case set-point control and (2) an off-peak ground pre-cool operating strategy. Simulations were conducted to predict the impact the proposed strategy has on energy consumption, operating cost, and peak power reduction for three suggested pre-cool schedules; shoulder, peak, and full season. The details of these proposed schemes will be further explained in the following section.

\section{METHODOLOGY}

The methodology applied in the presented study involves a three-part procedure. First, building energy simulations (BES) were conducted to generate estimates of the mid-rise building's annual hourly heating/cooling loads. Second, the annual hourly heating/cooling loads are utilized as input variables to design an economically optimized HGSHP system, following the rigorous computerized design methodology outlined in Alavy et al., (2013). The results of the BES and the optimized HGSHP are used as input parameters to the numerical performance prediction model. Further detail of the methodology applied in this study is provided in the following subsections.

\section{Building Energy Simulation and Hybrid System Design}

In this study, annual hourly thermal loads were generated for a mid-rise multi-residential building, located in Toronto, Canada using eQuest software. The simulated results initially allow for both heating and cooling to be supplied in a simultaneous fashion during each time interval. However, the heating and cooling loads are corrected under the assumption the building's demand can be satisfied with an internal mechanism before relying on the compensation from the geo-exchange system. In this analysis, a common water loop distribution system has been assumed, by neglecting the power consumption of the internal mechanism, the net demand will be provided by the GSHP to/from the common water loop distribution system. 
The computerized design methodology presented by Alavy et al., (2013) is used in this study to size an economically optimized HGSHP system. This design algorithm is based on the governing equations outlined in ASHRAE's design strategy (Kavanaugh and Rafferty 1997), automatically sizing the geo-exchange system and auxiliary equipment to meet peak building demands. Introducing a shave factor $(\alpha)$, defined as the portion of peak demand met by the geo-exchange system, the variable hybrid designs can be determined by fluctuating this factor between zero and one. The capital and operating costs for each shave factor value are calculated and discounted into a net present value. The optimal hybrid system design is selected for the shave factor associated to the lowest cost in net present value. The following Table 1 provides a summary of the modified hybrid design parameters selected in this study, all other variables were held constant, presented in Alavy et al. (2013).

Table 1. Summary of modified hybrid design parameters

\begin{tabular}{cccc}
\hline Parameter & Heat Pump & Entering Sink Temperature & EER \\
\hline \hline Cooling design specifications & $\begin{array}{c}\text { ClimateMaster Tranquility } \\
\text { TT }\end{array}$ & $25.1^{\circ} \mathrm{C}$ & \multirow{2}{*}{13.6} \\
\hline
\end{tabular}

For the HGSHP system design the ClimateMaster Tranquility TT heat pump is considered, with a dual stage heat pump unit capable of full load and 67\% part load operation. The auxiliary cooling system selected in this study is a nonreversible air-source heat pump (water-to-air), with an assumed average COP of 3.2 (Esen et al. 2007).

\section{Numerical Model}

In this study, in order to simulate and analyze the off-peak ground pre-cool control strategy, a numerical model was developed using MATLAB to characterize the operation of a HGSHP system for an annual duration. The model is deterministic in nature and simulates a load-based analysis determining which mechanical system has operational authority in each simulated time step. The model runs a yearly simulation with a time-step of 20 minutes for a total of 26,280 iterations. The generated model consisted of three primary inputs; annual hourly heating/cooling loads (eQuest), optimal HGSHP system specifications (Alavy et al., 2013), and TOU electrical cost structure (off-peak: $8.0 \phi / \mathrm{kWh}$, midpeak: $12.2 \mathrm{c} / \mathrm{kWh}$, peak: $16.1 \mathrm{c} / \mathrm{kWh}$ ). The input data is then processed to determine important characteristics of the building's thermal requirements, such as total heating/cooling demand required, peak heating/cooling loads, and whether the building under consideration is heating or cooling dominant. The capacities of the GSHP and auxiliary systems are then determined based on the optimal shave factor $(\alpha)$, defined as the percentage of peak cooling demand met by the geo-exchange system, with the remaining load $(1-\alpha)$ being supplied by the auxiliary systems. The numerical simulation is initiated as a set-point control algorithm fitted to the model is used to determine the operational authority of the sub-systems, depending on the building's thermal requirement in the current time-step. For every time-step of the numerical simulation, the portions of demand supplied by the geo-exchange system and the auxiliary systems are determined; the variation in the GSHP COP, and the bore-field average temperature response is predicted simultaneously.

The functionality of the variable GSHP is determined from a combination of experimental and numerically simulated results. The GSHP system transient COP response as a function of cycle time is estimated for experimental data presented by Alzahrani (2013). Utilizing the numerically generated data presented by Nam et al. (2015), a set of linear correlations were generated and used to predict the bore-field's response to pre-cooling and resulting impact on GSHP cooling output/COP. The developed numerical model simulates two physical responses to the presence of a pre-cooled bore-field, an increase in the rate of heat rejection to the ground during cooling operation (increase in cooling output) and an increase in the GSHP system COP (reduced compressor compensation). The increase in cooling output is due to the assumed reduction in ground temperature, resulting in an average increase in heat injection per meter length of the ground-loop. The increase in heat pump COP in cooling mode is due to an assumed reduction in compressor compensation, resulting from lower entering fluid temperatures. 


\section{Off-Peak Ground Pre-Cool Control Strategy}

The following Figure 1 is the proposed system orientation required to implement a ground pre-cool. The assumed hybrid configuration uses a series connection of the auxiliary cooling system with the ground-loop. The introduction of an additional operating loop is presented in Figure 1, accomplished by actuating V1 - V4 into their flow diverting state, resulting in the decoupling of the GSHP from the bore-field heat exchanger (BHE) circuit. With the auxiliary cooling system acting as the only active load, bore-field pre-conditioning would be made feasible. Figure 1 illustrates a simplified conceptual schematic of how pre-cool operation would be made feasible. The hybrid system model simulates the GSHP and ASHP in a series configuration on the distribution system (common water loop); during peak demand this configuration produces a net capacity capable of meeting the buildings requirements. Pre-cooling is accomplished through a secondary circulation loop coupling the ASHP to the ground-loop.

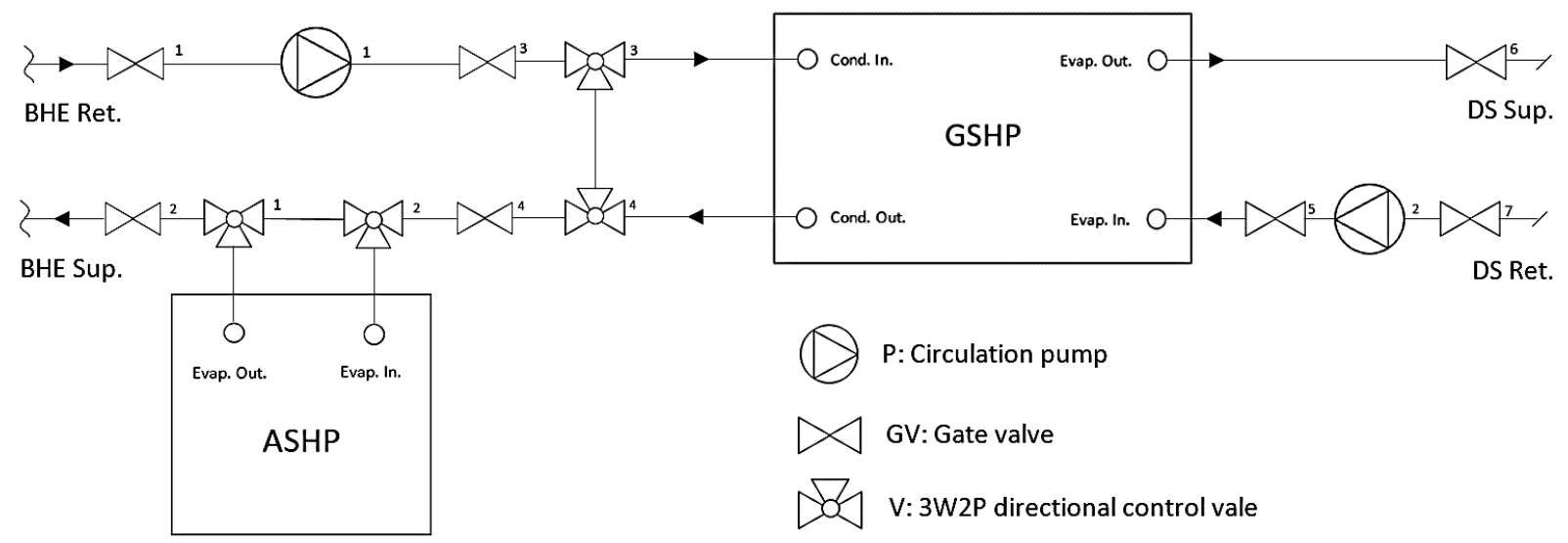

Figure 1 HGSHP Functional Schematic

The primary control technique used in the operation of the HGSHP system is a conventional set-point control scheme. This strategy is used in this study as a base case to reveal the potential benefits that an OGPC has on the operation of a HGSHP system. The OGPC algorithm's operational authority is restricted to the control of only the auxiliary cooling system, under the condition that specific logic indicators are satisfied. The preliminary stage of the OGPC strategy utilizes two control variables to determine the beginning of an OGPC cycle, being: time of the year and TOU operating bracket. The time of year was utilized as a control variable in the OGPC algorithm to permit flexibility in pre-cool operation, allowing for time spans of various cooling load densities to be targeted by the algorithm. In this study, three operating schedules were analyzed; 'shoulder season' (SS) operation (April 1st - May 31st), 'peak season' (PS) operation (July $1^{\text {st }}$ - August 31 st), and 'full season' (FS) operation (April $1^{\text {st }}$ - September 30th). The TOU control variable is a critical component in the OGPC algorithm where a pre-cool operation is strictly restricted to off-peak TOU brackets (19:00 - 7:00), taking full advantage of low electrical energy prices. For the suggested schedules, pre-cooling is designated to weekday operation, excluding weekends and holidays which are fixed to an off-peak utility rate.

\section{RESULTS}

The following sections present the simulated results for the mid-rise multi-residential building fitted with the three previously suggested off-peak pre-cool schedules. For this analysis, a single year of cooling season operation was evaluated, as the proposed operating strategy's scope is limited to improving system performance in cooling mode. The base case strategy utilizes the GSHP as the primary mechanical system, meeting base load demand, and is only assisted by the auxiliary cooling system when the demand exceeds the GSHP system's capacity. Table 2 presents a summary of the mid-rise's building energy simulation and optimal hybrid system design results. The results indicated an optimal 
shave factor of 0.23 for a peak cooling load of $274.5 \mathrm{~kW}$, with a resulting ground-loop length of 2115.5 meters. The building is characterized as cooling dominant, with a total heating-to-cooling ratio of 0.25 .

Table 2. Summary of building/hybrid system characteristics for the mid-rise

\begin{tabular}{ccccc}
\hline Peak Cooling Load & Shave Factor & Ground-Loop Length & Total Cooling Demand & Heating/Cooling Ratio \\
\hline \hline $274.5 \mathrm{~kW}$ & $23 \%$ & $2115.5 \mathrm{~m}$ & $573.7 \mathrm{MW}$ & 0.25 \\
\hline
\end{tabular}

\section{The Effect of Pre-Cool Duration on HGSHP System Performance}

To simulate the effect of the OGPC control strategy on the presented hybrid geo-exchange system, a primary analysis was conducted in which 36 unique annual simulations were carried out. In these analyses, only the pre-cool duration were varied; the simulations were conducted with 20 minute increments of pre-cool time, up to a maximum of 12 hours (full off-peak operating bracket). Upon completion of this study, the OGPC strategy was analyzed to determine the peak power reduction potential resulting from the introduced thermal benefit of the pre-conditioned bore-field. The simulations were conducted on the mid-rise building, for an optimally sized HGSHP system corresponding to a shave factor of $23 \%$.

Figure 2 presents the simulated results for the mid-rise building fitted with the proposed off-peak ground precool schedules, with the base case line acting as a datum reference for visual comparison. In Figure 2a, the mid-rise's AECC is presented as a function of pre-cool duration. It can be seen that all three pre-cool schedules exhibit similar trends, where longer pre-cool periods are required to realize the potential benefit for the proposed bore-field preconditioning. Both the shoulder season (SS) and full season (FS) schedules begin to illustrate energy savings potential after pre-cool periods greater than 8 hours. In Figure $2 \mathrm{~b}$, the mid-rise's ACC is presented for varying pre-cool durations. Figure $2 \mathrm{~b}$ indicates the shoulder season pre-cool schedule shows the greatest potential for operating cost savings for pre-cool periods greater than 9 hours; with negligible and no benefit illustrated with the FS and PS schedules, respectively. From the simulated results, it can be seen that the pre-cool strategy shows its greatest potential when implemented in a seasonal period of lower cooling load density (shoulder season). This benefit is realized because greater pre-conditioning can be accomplished due to a lower frequency of bore-field heat rejection.

a)

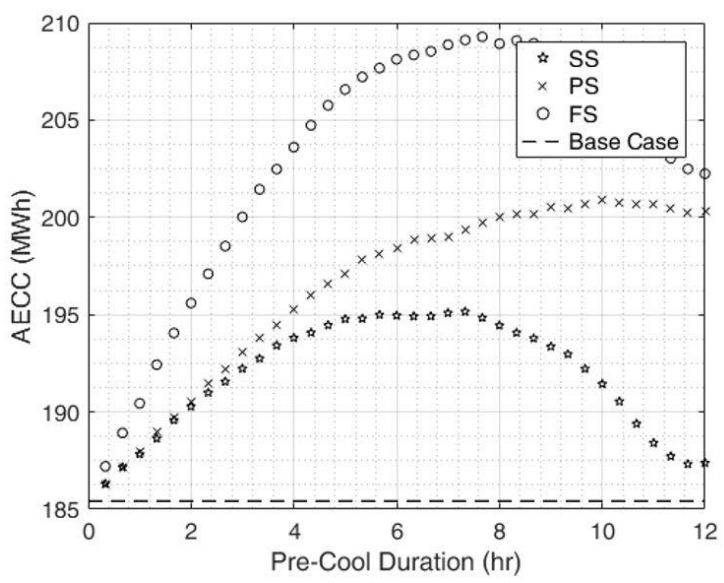

b)

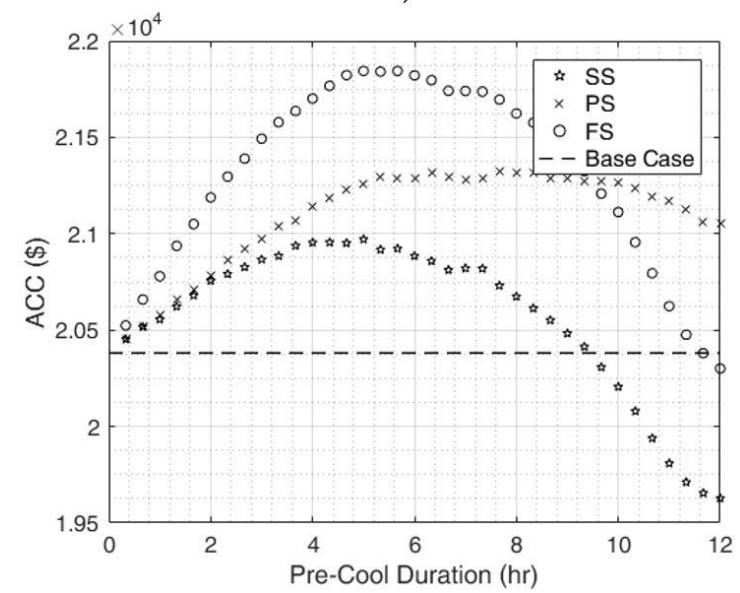

Figure 2 (a) AECC and (b) ACC versus pre-cool duration

Table 3 presents the simulated results for the mid-peak/peak power reduction potential for the mid-rise building. It can be seen that the three suggested pre-cool schedules indicate the potential for significant reduction in midpeak/peak power consumption. When considering the reduction potential associated to the peak season operating schedule, it is clear that there is less of an incentive for bore-field pre-conditioning during seasonal periods of typically high cooling load requirements; indicated by the lower mid-peak/peak power percent reduction. 
Table 3. Mid-peak/peak power reduction potential for proposed pre-cool schedules

\begin{tabular}{cccc}
\hline Operating Bracket & Shoulder Season (SS) & Peak Season (PS) & Full Season (FS) \\
\hline \hline Mid-Peak & $16.3 \%$ & $10.4 \%$ & $26.6 \%$ \\
Peak & $16.6 \%$ & $8.8 \%$ & $25.3 \%$ \\
\hline
\end{tabular}

\section{The Effect of HGSHP System Proportions on Pre-Cool Benefit}

To determine the proposed operating strategy's sensitivity to the hybrid system proportions, 99 unique simulations were conducted. In these simulations only hybrid system specifications were varied, corresponding to a shave factor of $1 \%-99 \%$, for a maximum pre-cool duration of 12 hours (full off-peak operating bracket). The scope of this analysis is to characterize the impact on the following outputs: annual electricity consumption for space cooling (AECC), annual cost for space cooling (ACC), and mid-peak/peak power consumption. For the following plots, each simulated data point represents an annual operating period for the respective hybrid shave factor with the corresponding pre-cool schedule; for which the meaning of a negative savings nullifies to a percent increase.

Figure $3 \mathrm{a}$ and Figure $3 \mathrm{~b}$ present the simulated results for the variation in annual electricity consumption and annual operating cost, respectively. For the mid-rise (Figure 3a) the slope of AECC savings has a positive trajectory for small shave factor values (under 20\%). In all three building cases the trajectory of the AECC savings profiles become negative for a shave factor range of approximately $20 \%$ to $60 \%$. After transitioning into a shave factor range of approximately $60 \%$ to $99 \%$, the slope of the AECC savings profiles becomes positive, converging at a shave factor of $99 \%$ with a predicted AECC savings percentage of zero.

It is illustrated that the proposed pre-cool control strategy has the smallest impact on system energy consumption for a shave factor range of approximately $5 \%$ to $20 \%$; where there is a negligible increase in total energy consumption for space cooling. When considering the potential economic benefit associated to the suggested pre-cooling strategy, similar trends as those present in the AECC savings profiles (Figure 3a) occur. In Figure 3b, the scheduled ground preconditioning shows potential for improved system economics, occurring for undersized hybrid systems (low shave factor values). The ACC savings potential occurs for a shave factor range of approximately $5 \%-40 \%$; with the maximum potential for ACC savings occurring on the lower end of the range and gradually degrading as the upper limit is reached. For the mid-rise building a shoulder season (SS) pre-conducting schedule shows the least sensitivity to variation in hybrid system proportions.

To conceptualize the physical meaning of trends addressed in Figure 3a, the significance of the hybrid system shave factor must be understood. The shave factor parameter represent the percentage of a buildings peak cooling demand met by the GSHP, with the difference being supplied by the auxiliary cooling system. For example, if a building requires $100 \mathrm{~kW}$ of peak cooling and a shave factor design of $10 \%$ is selected, the resulting cooling capacity of the GSHP and auxiliary cooling system are $10 \mathrm{~kW}$ and $90 \mathrm{~kW}$, respectively. When the shave factor is varied, three hybrid system parameters change: ground-loop length, GSHP system cooling capacity, and auxiliary system cooling capacity. From the simulation results, undersized hybrid systems are most promising for this strategy due to smaller ground-loop lengths (meaning smaller bore-field/soil volumes) and large auxiliary cooling capacity, which would translate to faster ground temperature response. This concept is further illustrated for shave factor values of $1 \%$ and $99 \% ; 1 \%$ representing the smallest hybrid system configuration (large auxiliary cooling capacity and small ground-loop length) resulting in excessive energy consumption from pre-cooling with insufficient GSHP operating benefit, due to an undersized borefield heat exchanger. Alternatively, a shave factor of 99\% represents the largest hybrid system configuration (small auxiliary cooling capacity and large ground-loop length) resulting in negligible energy consumption increase from precooling and negligible thermal impact on the bore-field, due to large bore-field/soil volumes. 
a)

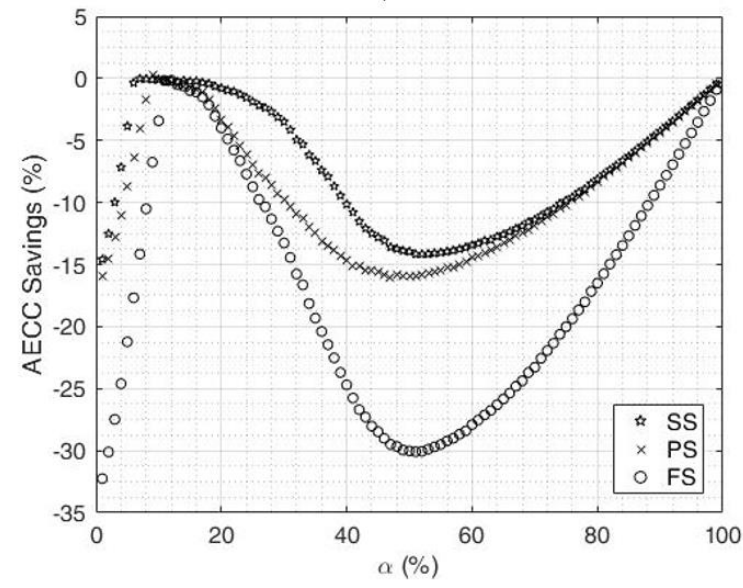

b)

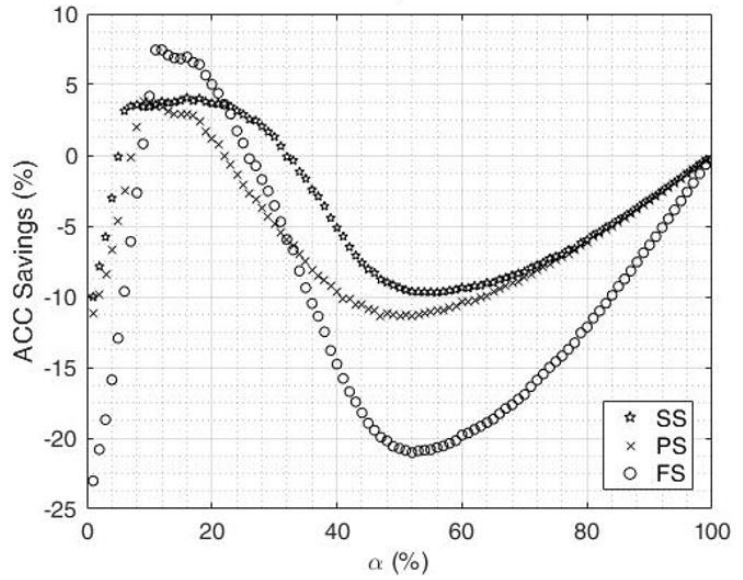

Figure 3 (a) AECC and (b) ACC, savings potential versus hybrid system shave factor $(\alpha)$

The predicted annual mid-peak and peak power reduction sensitivity to hybrid system proportions are presented in Figure 4a and Figure 4b, respectively. The mid-rise building simulations depict consistent trends with regard to midpeak/peak power reduction potential. In this case, maximum peak power reduction occurs within a shave factor range of $5 \%$ to $40 \%$. As the hybrid system size increases past a shave factor of $40 \%$, mid-peak/peak power reduction degrades until a negligible impact on the results, at a shave factor of approximately $60 \%$.

a)

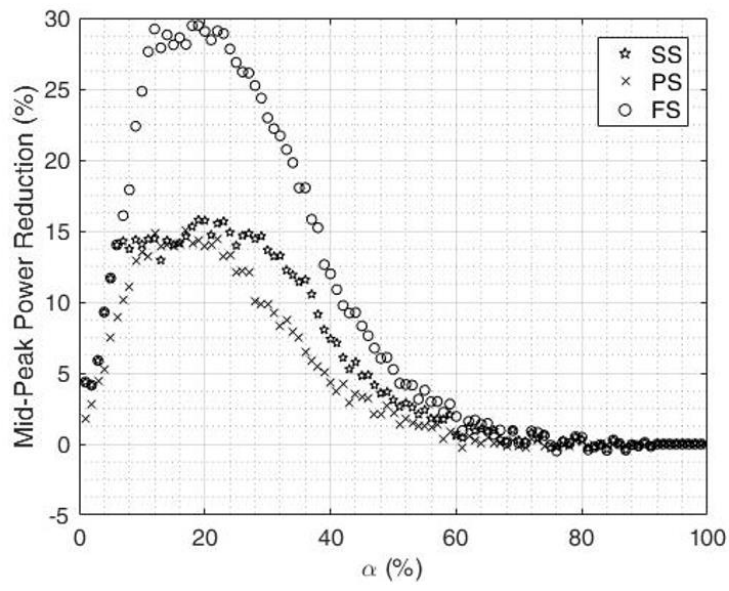

b)

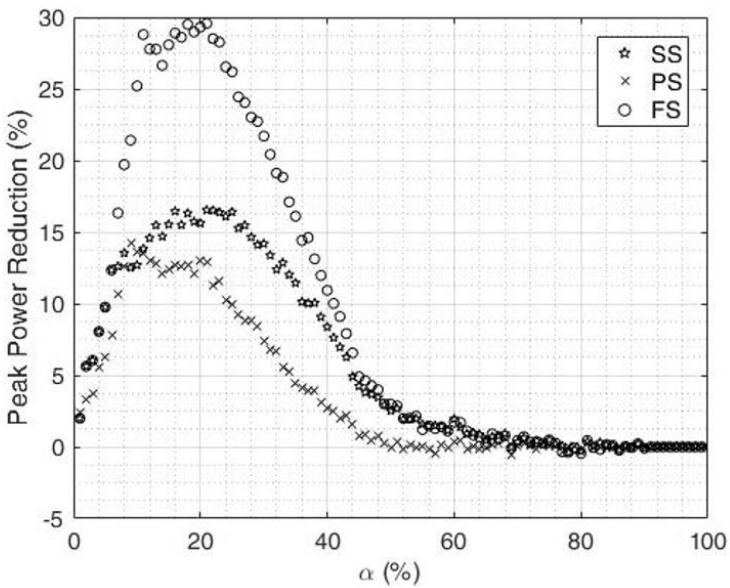

Figure 4 (a) Mid-peak and (b) peak, power reduction potential versus hybrid system shave factor $(\alpha)$ 


\section{CONCLUSION}

The analyses in this paper present a preliminary evaluation demonstrating the potential benefit that an off-peak ground pre-cool control strategy has on a HGSHP system's performance. A three-step evaluation procedure was implemented, consisting of: an eQuest building energy simulation, a computerized HGSHP design procedure (Alavy et. al 2013), and numerical simulations of a HGSHP operating over a cooling season (conducted with the aid of a newly developed numerical performance prediction model). This study was led for a mid-rise multi-residential building, located in Toronto, Canada. Two analyses were carried out, evaluating the bore-field pre-conditioning strategy's sensitivity to various simulation parameters. First, the impact of pre-cool duration was evaluated for an optimally sized HGSHP, predicting the response of the proposed shoulder, peak, and full season schedules for varying pre-cool duration. Secondly, the impact of HGSHP proportions was studied for system sizes in the shave factor range of $1 \%$ to $99 \%$. The following is a summary of the significant findings and conclusions drawn from the analyses conducted on the mid-rise building:

- The potential benefit proposed by the OGPC strategy is sensitive to a building's cooling load characteristics. No economic benefit was indicated for pre-cool schedules during operating periods with greater frequency/amplitude of cooling requirements (due to increased heat rejection to the bore-field). However, positive trends were generated with regard to mid-peak/peak power reduction potential.

- A shoulder season (SS) operating schedule indicated the greatest potential for a reduction in operating cost. The shoulder season simulations suggested the least sensitivity to variations in hybrid system proportions, indicating the greatest potential for an economic benefit with a larger range of system sizes.

- Undersized hybrid systems are most promising for the integration of an OGPC strategy due to smaller groundloop lengths (meaning smaller bore-field/soil volumes) and large auxiliary cooling capacity, translating to faster ground temperature response.

The proposed control methodology suggests an alternative perspective for the operation of HGSHP systems, targeting the improvement of system economics through a reduction in peak power consumption. The analyses performed in this paper shed light on the potential trends that would occur for the physical implementation of an OGPC control strategy. Due to the complexity of the proposed operating concept, further research and development is required to provide a detailed characterization of the benefit that an OGPC control poses for the operation of HGSHP systems.

\section{ACKNOWLEDGMENTS}

The authors would like to acknowledge Dr. Stanley Reitsma of GeoSource Energy Inc., a full service energy design-build company focused on geo-exchange systems, for advising the research and providing technical expertise. The authors would also like to thank the Faculty of Engineering and Architectural Science at Ryerson University, NSERC, and the Ontario Graduate Scholarship for their financial support. 


\section{REFERENCES}

Alavy, M.., H.V Nguyen, W.H Leong, S.B. Dworkin. 2013. A Methodology and Computerized Approach for Optimizing Hybrid Ground Source Heat Pump System Design, Renewable Energy, vol. 57, pp.404-412.

Alzahrani, W.. 2013. Experimental Study of the Performance of a Vertical and a Horizontal Ground Loops Coupled to a Ground Source Heat Pump System, MASC Thesis, Department of Mechanical and Industrial Engineering, Ryerson University, Toronto.

Carvalho, A. D., P. Moura, G. C. Vaz and A. T. de Almedia. 2015. Ground source heat pumps as high effficient solutions for building space conditioning and for integration in smart grids, Energy Conservation and Managment, vol. 103, pp. 991-1007.

EIA, USA, 2012. Monthly energy review: energy consumption by sector, Available: http://www.eia.gov/totalenergy/data/monthly/\#consumption.

Esen, H., M. Inalli, M. Esen 2007. A techno-economic comparison of ground-coupled and air-coupled heat pump systems for space cooling, Building and Environment, vol. 42, pp. 1955-1965.

Hackel, S. and A. Pertzborn. 2011. Effective Design and Operation of Hybrid Ground-Source Heat Pumps: Three Case Studies, Energy and Buildings, vol. 43, pp. 3497-3504.

Jassen, E., D. Zhang and T. VanSeters. 2015. Performance assessment of ubran geo-exchange projects in the greater Toronto area, Toronto and Region Conservation Authority Technical Report , Toronto. Available:

http://www.sustainabletechnologies.ca/wp/wpcontent/uploads/2015/03/GeoExchangeMonitoring_Final_Feb2015.p df

Kavanaugh, S.P. \& K. Rafferty. 1997. Ground-source heat pumps: Design of geothermal systems for commercial and institutional buildings. Atlanta, Georgia: American Society of Heating Refrigerating and Air-Conditioning Engineers, Inc.

Nam, Y. J. , X. Y. Gao , S. H. Yoon and K. H. Lee. 2015. Study on the performance of a ground source heat pump system assisted by solar thermal storage, Energies, vol. 8, pp. 13378-13394.

NRCan, 2013. Energy Use Hata Table. Available: http://oee.nrcan.gc.ca/corporate/statistics/neud/dpa/showTable.cfm?type $=$ HB\&sector $=$ aaa\&juris $=$ ca\&rn $=2 \& p a g e=$ $6 \& C F I D=30320730 \&$ CFTOKEN.

Verma, V. and K. Murugesan. 2014. Optimization of solar assisted ground source heat pump system for space heating application by Taguchi method and utility concept, Energy and Buildings, vol. 82, pp. 296-309. 